Running head: Self-enhancement in autobiographical memory

$$
2008 \text { - Memory, 16, 534-547 }
$$

\title{
Remembering pride and shame: Self-enhancement and the phenomenology of autobiographical memory
}

\author{
Arnaud D’Argembeau \\ University of Liège, Belgium \\ Belgian National Fund for Scientific Research (FNRS) \\ Martial Van der Linden \\ University and Geneva, Switzerland, and University of Liège, Belgium
}

Correspondence concerning this article should be addressed to Arnaud D'Argembeau, Department of Cognitive Sciences, University of Liège, Boulevard du Rectorat 3 (B33), B4000 Liège, Belgium. Tel: +32 4366 4657; fax: +32 4366 2808. email: a.dargembeau@ulg.ac.be 


\begin{abstract}
People's self-images are grounded in autobiographical memories and, in particular, in the phenomenological experience associated with remembering. The desire to increase or maintain the positivity of the self-image (i.e., the self-enhancement motive) might thus play an important role in shaping memory phenomenology. This study examined this hypothesis by asking participants to recall positive and negative events that involve self-evaluations (i.e., pride and shame) and positive and negative events that involve evaluations about others (i.e., admiration and contempt); various phenomenological characteristics (e.g., sensory details, feeling of re-experiencing) were assessed using rating scales. The results show a positivity bias (i.e., subjectively remembering positive events with more details than negative events) for events that involve self-evaluations but not for events that involve evaluations of others. In addition, this bias was stronger for people high in self-esteem. It is concluded that biases affecting the phenomenology of autobiographical memory are part of the arsenal of psychological mechanisms people use to maintain a positive self-image.
\end{abstract}


Remembering an event does not consist in "playing" or "reading" a literal record of the past, it is a constructive process in which bits and pieces of information from various sources (e.g., perceptual, contextual, semantic, emotional details) are re-combined together in order to mentally reconstruct the past experience (Conway, 2005; Johnson, 2006; Schacter \& Addis, 2007). As a consequence, memory is prone to various kinds of errors, illusions, and distortions (Schacter, 1999). Biases and distortions in the way we remember our personal past originate, in part, from self-related motives. In particular, Conway recently proposed that memory is strongly influenced by demands of coherence between memories and the self (Conway, 2001, 2005; Conway, Singer, \& Tagini, 2004). The self and memories have to form a coherent system, in which each component informs and constrains the other; what is encoded, maintained, and retrieved in priority is information that is consistent with an individual's goals, self-images, and self-beliefs, and reciprocally, beliefs and knowledge about oneself are grounded in memories of specific experiences (Conway et al., 2004). In a similar vein, McAdams (2001) has argued that identity consists of an internalized and evolving story of self that is based on autobiographical memories as well as future expectations. McAdams further emphasized that life stories are constructions and that some remembered episodes are more privileged for self-definition than are others. Although healthy people's memories are of course not completely disconnected from reality, they tend to be altered, distorted, and may even be fabricated to support the self-concept (Conway, 2005; Greenwald, 1980; Wilson \& Ross, 2003). "To a certain degree, then, identity is a product of choice. We choose the events that we consider most important for defining who we are" (McAdams, 2001, p. 110).

Perhaps the most powerful self-related motive is the desire to maintain or increase the positivity of one's self-concept (i.e., the self-enhancement motive; Baumeister, 1998; Leary, 2007; Sedikides \& Gregg, 2003). Various strategies are used to achieve this goal: for 
example, people tend to take more responsibility for success than failure, to compare themselves with others that are worse than they are, and to distance themselves from those who outperform them (for reviews, see Baumeister, 1998; Leary, 2007; Sedikides \& Gregg, 2003). Research also suggests that the self-enhancement motive influences what we remember about ourselves. First, studies of the self-reference effect (Rogers, Kuiper, \& Kirker, 1977) show that positive information (e.g., trait adjectives such as "kind") is better recalled than negative information (e.g., trait adjectives such as "dishonest") when it is processed in relation to the self, but not when it is related to another person or when it is processed for general meaning (D'Argembeau, Comblain, \& Van der Linden, 2005; Denny \& Hunt, 1992; Kuiper \& Derry, 1982; Sanz, 1996; Sedikides \& Green, 2000; Sedikides \& Green, 2004). Second, some studies have revealed a series of biases in the functioning of autobiographical memory that probably contributes to enhance and maintain positive selfviews. For example, research by Ross and colleagues indicates that self-enhancement goals influence people's subjective judgments of when a past episode occurred (Wilson \& Ross, 2003). They showed, in particular, that people tend to feel farther from past failures than from past achievements, even when calendar time does not differ (Ross \& Wilson, 2002). Other studies demonstrated that the affective intensity of autobiographical memories fades more rapidly for negative than for positive events, thus giving people a heightened sense of positivity when remembering life events (reviewed in Walker, Skowronski, \& Thompson, 2003). Exploring disputes over memory ownership in twins, Sheen, Kemp, and Rubin (2006) observed that twins tend to claim for themselves memories of achievements, and are more likely to give away memories of personal wrongdoing. Finally, some studies suggest that the content of confabulations is not random, but rather reflects the operation of self-enhancement motives (Conway \& Tacchi, 1996; Fotopoulou, Conway, Griffiths, Birchall, \& Tyrer, 2007; Fotopoulou, Conway, \& Solms, 2007). 
A defining feature of autobiographical memory is the phenomenological experience associated with remembering. Remembering an event is accompanied by a particular state of consciousness that consists of, for example, "seeing" in one's mind the location where the event took place and the persons who were present, feeling the emotions one felt at the time, and so forth (Johnson, Foley, Suengas, \& Raye, 1988; Rubin, Schrauf, \& Greenberg, 2003). The particular configuration of sensory, contextual, semantic, and emotional features that is experienced while remembering an event gives rise to the feeling of mentally re-experiencing the past (i.e., recollective experience), which is the hallmark of episodic memory (Conway, 2005; Tulving, 2002; Wheeler, Stuss, \& Tulving, 1997). Recollective experience in turn influences the perceived or subjective truth of the memory (whether it is actually accurate or not is a different issue; Johnson, 2006) and determines the power of the memory in shaping self-images. A memory that is experienced as containing highly detailed sensory, contextual, and emotional features will provide more information to exemplify, contextualize, and ground core beliefs about the self. The desire to maintain or increase the positivity of the self-concept should thus exert particularly strong influences on the phenomenological experience associated with remembering, leading to the formation of more detailed memories for events that convey favourable views of the self. Surprisingly, however, the handful of studies that examined the subjective qualities of autobiographical memories for positive versus negative events have led to inconsistent results. Some studies found that memories for positive events are subjectively experienced with more details than memories for negative events (Byrne, Hyman, \& Scott, 2001; Bywaters, Andrade, \& Turpin, 2004; D'Argembeau, Comblain, \& Van der Linden, 2003; D'Argembeau \& Van der Linden, 2004; Destun \& Kuiper, 1999; Schaefer \& Philippot, 2005). However, other studies detected very few differences between positive and negative events (Bohanek, Fivush, \& Walker, 2005; Comblain, D'Argembeau, \& Van der Linden, 2005) or found that emotional intensity is a better predictor of autobiographical 
memory experience than emotional valence (Reisberg, Heuer, McLean, \& O'Shaughnessy, 1988; Talarico, LaBar, \& Rubin, 2004).

A possible explanation of these conflicting findings is that the sampled events varied in terms of their relevance to the self-image. For example, when asked to remember positive and negative events in a previous study, participants recalled events that had direct implications for their self-image (e.g., episodes of success or failure at school), but also events that were less related to the self-concept (e.g., having fun at a party, being informed of the death of a friend; D'Argembeau et al., 2003). Such mixing of self-relevant and non-selfrelevant events might blur valence effects presumably related to the self-enhancement motive. Insofar as biases towards subjectively remembering positive events with more details than negative events serve the self-enhancement motive, they should be specifically apparent when remembering events that have direct implications for the self-image. The primary purpose of this study was to test this hypothesis, by investigating the influence of valence on memories for events that entail a strong self-evaluative component. From this perspective, selfconscious emotions such as pride and shame are particularly interesting to examine, as they are evoked by positive or negative evaluations about the self (Leary, 2007; Tangney, 2003). In this study, these two self-conscious emotions were compared to positive and negative emotions arising from evaluations targeting another person (i.e., admiration and contempt). Our hypothesis is that the valence (positive vs. negative) and target (self vs. other) of evaluations should interact to influence the phenomenological characteristics of memories, such that a positivity bias should be apparent for events that involve evaluations of the self but not for events that involve evaluations of someone else.

The second purpose of this study was to explore whether biases in autobiographical memory are modulated by individual differences in the positivity of the self-image. If autobiographical memory biases are indeed related to the self-enhancement motive, they 
should be stronger for people who succeed in maintaining a positive view of the self, such as people high in self-esteem. More specifically, a stronger motivation to maintain and increase the positivity of the self-image should led people high in self-esteem to construct more detailed memories for positive self-relevant events. Some previous autobiographical memory studies have shown that self-esteem influences memory for previous emotional reactions, with high self-esteem individuals recalling their reactions in a more positive way (Christensen, Wood, \& Feldman Barrett, 2003; Sutin \& Robins, 2005). A recent study has further revealed that high self-esteem individuals rate personally meaningful (self-defining) memories as more vivid, coherent, accessible, and positively valenced (Sutin \& Robins, 2007). However, the extent to which the influence of self-esteem is limited to memories for self-relevant events has not been investigated. In the current study, we examined this issue by comparing individuals high and low in self-esteem. We expected that high self-esteem individuals would present a stronger positivity bias for events that involve evaluations of the self but not for events that involve evaluations of someone else.

\section{Method}

\section{Participants}

A total of 64 women and 48 men aged between 18 and 55 years volunteered to participate in the study. From these, two groups of participants were selected on the basis of their scores on the Rosenberg self-esteem scale (RSE), a widely used 10-item measure of selfesteem (Rosenberg, 1965; French adaptation by Chambon et al., 1992). Participants who scored in the top quartile (score $\geq 34 ; M=36.1, S D=2.0$ ) were defined as high self-esteem (HSE) individuals ( 11 women and 17 men aged between 20 and 54 years; $M=30$ years, $S D=$ 12), whereas participants who scored in the bottom quartile ( score $\leq 27 ; M=24.2, S D=3.3$ ) 
were defined as low self-esteem (LSE) individuals ( 20 women and 9 men aged between 18 and 55 years; $M=26$ years, $S D=10)$.

\section{Materials and procedure}

Participants were tested individually in a quiet environment. Detailed instructions explained that they would be asked to remember some events they had personally experienced in the past. The instructions specified that the events participants were to recall had to be precise and specific (i.e., they had to take place in a specific place at a specific time and they had to last a few minutes or hours but not more than a day); some examples were provided to illustrate what would or would not be considered as a specific event. Participants were asked to remember four events that varied according to valence (positive vs. negative) and target (self vs. other) of emotional evaluations: an event in which they felt proud of themselves, an event in which they felt ashamed of themselves, an event in which they felt admiration towards someone, and an event in which they felt contempt towards someone. For each event, participants were asked to try to remember the event in as much detail as possible (i.e., remembering the setting and course of the events, the persons and objects that were present) in order to mentally "re-experience" it. Immediately after having remembered each event, participants wrote a brief description of the event and rated their subjective experience with 7point rating scales. Memories were assessed for feeling of re-experiencing, visual details, other sensory details, location, time, coherence, verbal component, emotion while remembering, belief that the event is real, emotional valence, personal importance, and reactivation, using rating scales adapted from the Memory Characteristics Questionnaire (Johnson et al., 1988) and the Autobiographical Memory Questionnaire (Rubin et al., 2003). We added three items to asses memory for self-referential information (i.e., what one did, what one said, and what one thought during the event), and participants also assessed the 
visual perspective they adopted while remembering (Nigro \& Neisser, 1983). Finally, the age of each event was also recorded (in months). The rating scales that were used in this study are shown in Table 1. The order of presentation of the four types of events was counterbalanced across participants.

(Table 1 about here)

\section{Results}

Mean ratings for each phenomenological characteristic are shown in Table 2, as a function of self-esteem (HSE vs. LSE), valence (positive vs. negative), and target (self vs. other). Initial analyses did not reveal any effect of gender or interaction involving gender, so data from women and men are combined in the reported analyses. For each characteristic, the ratings were submitted to a 2 (self-esteem) X 2 (target) X 2 (valence) analysis of variance (ANOVA). As predicted, the ANOVA yielded a significant valence by target interaction for several phenomenological characteristics, showing that the effect of valence was modulated by evaluation target. This was the case for feeling of re-experiencing, $F(1,55)=5.53, M S E=$ $2.36, p=.02$, other sensory details, $F(1,55)=4.48, M S E=2.14, p=.04$, coherence, $F(1,55)$ $=21.69, M S E=1.60, p<.001$, verbal component, $F(1,55)=4.72, M S E=2.09, p=.03$, belief that the event is real, $F(1,55)=5.15, M S E=0.57, p=.03$, memory for what one did, $F(1,55)$ $=8.33, M S E=1.78, p=.01$, importance, $F(1,55)=13.06, M S E=2.84, p<.001$, and reactivation, $F(1,55)=9.05, M S E=2.75, p=.003$. The means were also in the predicted direction for memory for location and memory for what one said, but the valence by target interaction failed to reach statistical significance, $F(1,55)=3.58, M S E=1.29, p=.06$, and $F(1,55)=3.24, M S E=3.16, p=.077$, respectively. Follow-up comparisons showed that positive self-relevant events received higher ratings than negative self-relevant events for feeling of re-experiencing $[t(56)=2.95, p=.005, d=.40]$, other sensory details $[t(56)=2.43$, 
$p=.02, d=.32]$, coherence $[t(56)=3.05, p=.004, d=.41]$, belief that the event is real $[t(56)$ $=3.41, p=.001, d=.46]$, memory for what one $\operatorname{did}[t(56)=2.15, p=.04, d=.29]$, importance $[t(56)=6.36, p<.001, d=.85]$, and reactivation $[t(56)=3.01, p=.004, d=.40]$, whereas there was no difference between positive and negative events that targeted another person [all $t(56) \mathrm{s}<1, p \mathrm{~s}>.33, d \mathrm{~s}<.14$ ] or the difference was reversed [for coherence, $t(56)=$ $2.76, p<.05, d=.37$, and for what one did, $t(56)=1.89, p=.06, d=.25]$. For verbal components, there was no difference between positive and negative events that targeted the self, $t(56)=1.01, p=.32, d=.13$; negative events tended to receive higher ratings than positive events when they targeted another person, $t(56)=1.88, p=.06, d=.25$.

For other phenomenological characteristics, the ANOVA yielded a three-way interaction, indicating that the effect of valence was modulated by both self-esteem and the target of events. This was the case for visual details, $F(1,55)=4.35, M S E=2.08, p=.04$, time, $F(1,55)=4.52, M S E=2.64, p=.04$, feeling of emotions, $F(1,55)=4.51, M S E=2.75$, $p=.04$, and memory for what one thought, $F(1,55)=4.93, M S E=1.63, p=.03$. To further investigate these three-way interactions, 2 (valence) X 2 (target) ANOVAs were conducted separately for HSE and LSE individuals. For each characteristic, there was a significant valence by target interaction for HSE individual [all $F(1,27) \mathrm{s}>4.66, p \mathrm{~s}<.05$ ], but not for LSE individuals [all $F(1,28) \mathrm{s}<1.44, p \mathrm{~s}>.24]$. Follow-up comparisons showed that HSE individuals rated memories for positive events targeting the self as containing more visual details $[t(27)=4.27, p<.001, d=.82]$, clearer information about time $[t(27)=3.20, p=.004$, $d=.62]$, more emotional feelings during remembering $[t(27)=2.63, p=.01, d=.51]$, and clearer memory for thoughts $[t(27)=2.28, p=.03, d=.44]$ than memories for negative events targeting the self; by contrast, there was no valence effect for events that targeted another person [for visual details and time, $t(27) \mathrm{s}<1, p \mathrm{~s}>.63, d \mathrm{~s}<.10$ ] or the effect was reversed 
[for feeling emotions, $t(27)=2.96, p=.006, d=.57$, and thoughts, $t(27)=2.31, p=.03, d=$ $.44]$.

(Table 2 about here)

Finally, visual perspective showed a main effect of target, $F(1,55)=4.97, M S E=$ $3.39, p=.03$, with events targeting the self being remembered more with an observer perspective than events targeting another person; there was no other main effect or interaction [all $F(1,55) \mathrm{s}<1.59, p \mathrm{~s}>.20$ ]. Ratings of valence showed a main effect of self-esteem, $F(1$, $55)=5.48, M S E=1.59, p=.02$ (ratings were higher in HSE individuals), a main effect of target, $F(1,55)=26.64, M S E=2.35, p<.001$ (ratings were higher for events targeting the self), and a main effect of valence, $F(1,55)=453.94, M S E=1.07, p<.001$ (ratings were higher for positive events), but no interaction between these factors [all $F(1,55) \mathrm{s}<1.14, p s>$ .29]. There was no significant main effect or interaction with regard to event age [all $F(1,55) \mathrm{s}$ $<3.27, p s>.07]$.

\section{Discussion}

The purpose of this study was to examine whether the phenomenological experience associated with remembering positive and negative events is modulated by the relevance of events to the self-image. Participants were asked to recall positive and negative events that involved self-evaluations (i.e., pride and shame) and positive and negative events that involved evaluations about someone else (i.e., admiration and contempt); the phenomenological experience associated with remembering each type of event was assessed using a series of rating scales. We expected to observe a positivity bias consisting of subjectively remembering positive events with more details than negative events, but only for events that entail self-evaluations. In agreement with this prediction, we found that the valence and target of events interacted to influence memory characteristics. More specifically, 
memories for pride episodes were associated with increased feelings of re-experiencing and a stronger belief that the event was real, contained more sensory details such as sounds, smells and tastes and more details about what one did, were considered as more important, and had been reactivated more frequently than memories for shame episodes; these differences between positive and negative memories did not occur (or were even reversed) for events targeting another person (i.e., episodes involving admiration vs. contempt). For other phenomenological characteristics, biases in remembering self-evaluative events were modulated by participants' level of self-esteem, such that memories for pride episodes contained more visual details, clearer information about time, more details about what one thought, and were associated with more emotional feelings during remembering (relative to memories for shame episodes), but only for participants high in self-esteem. These latter findings are consistent with and extend previous studies (Christensen et al., 2003; Sutin \& Robins, 2005, 2007), providing evidence that the influence of self-esteem is specific to memories for self-relevant events. Importantly, the reported effects cannot be simply explained in terms of differences in event age, as there was no significant main effect or interaction concerning this dimension.

Overall, the current findings support our claim that the self-enhancement motive shapes the phenomenological experience associated with remembering positive versus negative events. First, the effect of valence was clearly modulated by the target of emotional evaluations, such that a positivity bias was only apparent for events involving selfevaluations. Second, this bias was more pronounced (i.e., affected more memory characteristics) for people who succeed in creating and maintaining a positive view of the self (i.e., people high in self-esteem). As already mentioned, the functioning of autobiographical memory is influenced by motives to maintain or promote certain kinds of self-images and, reciprocally, self-images are grounded in memories for personal experiences (Conway, 2005; 
Conway et al., 2004). The phenomenological qualities of memories undoubtedly play an important role in this process, determining the power of the memories in shaping self-images. Remembering self-flattering episodes in a more detailed way, having a higher feeling of mentally re-experiencing them and a stronger belief that they were real thus provide valuable resources to ground positive self-views in past experiences. These biases in the phenomenology of memories for self-relevant episodes are probably an important part of the arsenal of psychological mechanisms people use to increase or maintain a positive self-image (along with biases in attention, judgment, and attribution; Baumeister, 1998; Leary, 2007; Sedikides \& Gregg, 2003).

Having demonstrated the existence of a positivity bias in the subjective experience associated with remembering self-relevant episodes, we now discuss the mechanisms that might underlie this bias. It is likely that the influence of self-enhancement operates at multiple stages of memory processing. First, self-enhancement motives might affect attention and elaborative processing during memory encoding. There is indeed evidence that people engage less processing resources when encoding negative compared to positive self-relevant information (Sedikides \& Green, 2000). People may also control the retrieval of stored information, favoring access to positive rather than negative self-relevant information (D'Argembeau et al., 2005). In particular, Conway (Conway, 2005; Conway \& PleydellPearce, 2000) proposed that the self modulates the accessibility of knowledge in autobiographical memory in order to increase access to information that is consistent with goals and self-knowledge and to decrease access to information that challenges selfknowledge and might thus be destabilizing. Such control processes might shape the phenomenology of memories throughout the retrieval process to favor the construction of detailed representations of pride rather than shame episodes. The influence of individual differences in self-esteem might also be explained, at least in part, in terms of control 
processes that modulate the accessibility of autobiographical knowledge. Indeed, Sutin and Robins (2007) recently reported that individuals with high self-esteem rate their self-defining memories as more accessible and more positively valenced. Finally, we found that memories for pride episodes had been reactivated (through thinking and/or social sharing) more frequently than memories for shame episodes. Reactivation of memories strengthens associations between the memory constituents (e.g., objects, people, actions, and feelings; Johnson \& Chalfonte, 1994), and helps maintain the episode in memory for longer periods of time by linking it to conceptual knowledge regarding long-term goals and self-images (Conway, 2001, 2005). Conversely, research shows that repeated attempts to avoid the retrieval of a memory decrease its subsequent accessibility (Anderson \& Green, 2001), and functional neuroimaging suggests that these processes recruit the lateral prefrontal cortex to disengage hippocampal processing that supports recollection (Anderson et al., 2004). This type of inhibitory mechanisms may be recruited in everyday life to prevent unwanted memories from entering consciousness (Anderson, 2006). Differences in the frequency of reactivations of positive versus negative self-relevant memories may thus have modulated the current accessibility of these memories and, consequently, the phenomenological experience associated with retrieval. These propositions remain speculative, however, and further studies need to be conducted in order to uncover the precise cognitive and neural mechanisms that underlie self-enhancement biases in the phenomenology of autobiographical memories and, in particular, to determine the respective contribution of facilitative versus inhibitory processes. Contrary to most other phenomenological characteristics, the visual perspective of the memories did not show any trace of self-enhancing influences. Considering that observer memories can serve a distancing function (Libby \& Eibach, 2002), one could expect that people would report more observer memories for negative events targeting the self. We found that events targeting the self were remembered more with an observer perspective than events 
targeting another person, which is consistent with previous findings that situations associated with higher levels of self-awareness are more likely to be recalled with an observer perspective (Nigro \& Neisser, 1983). However, this effect was not modulated by event valence (see also D’Argembeau et al., 2003; D’Argembeau \& Van der Linden, 2004). Thus, there was no evidence for a distancing function of the observer perspective in this study.

Finally, it should be noted that, although participants displayed a general tendency to remember pride episodes with more details than shame episodes, memories for shame episodes did not completely lack details (as can be seen in Table 2, mean ratings for most phenomenological characteristics still fell above the midpoint of the rating scales). Selfenhancement is associated with psychological gains (e.g., subjective well-being, persistence in the pursuit of one's goals, better coping with adverse situations; Taylor \& Brown, 1988) but it can also lead to intrapersonal and interpersonal costs (e.g., excessive risk taking, being perceived negatively and treated unpleasantly by others; Leary, 2004). It is therefore important to have a sufficiently balanced view of the self that is not too much disconnected from reality (Leary, 2004; Sedikides, Gregg, \& Hart, 2007). Subtle differences in the way people subjectively remember positive and negative self-relevant experiences might help maintain a positive view of the self, while at the same time keeping a sufficiently balanced view of the self. In addition, it is likely that the ability to access negative information about oneself varies according to circumstances. In particular, when dealing with a difficult situation in the present or when envisioning how to face such a situation in the future, it is sometimes advantageous to acknowledge one's own shortcomings and remember past failures in similar events in order to better handle the present or future circumstances. In other words, memories of past failures warn us of problems that have been encountered in the past (e.g., unwanted consequences of a particular behavior) and motivate us to make decisions and take action to avoid repeating similar problems in the future (D'Argembeau \& Van der Linden, 
2007). Thus, most people may display a general tendency to inhibit access to information that might tarnish the self-image, yet negative self-referent information might still be accessed to form a balanced view of the self and to adjust to situations where accurate estimations of one's own shortcomings and knowledge about past failures help make advantageous decisions.

In conclusion, the current study comforts the view that autobiographical memory is motivated (Conway, 2005) and suggests, in particular, that self-enhancement motives play an important role in shaping the phenomenology of autobiographical memories. Subjectively remembering pride episodes with more details than shame episodes, having a higher feeling of mentally re-experiencing and a stronger belief that the events were real probably play an important role in creating and maintaining a positive view of the self. Future studies should be conducted to uncover the precise cognitive and neural processes that underlie this phenomenon and to investigate how it might vary according to contextual factors. 
References

Anderson, M. C. (2006). Repression: A cognitive neuroscience approach. In M. Mancia (Ed.), Neuroscience and psychoanalysis (pp. 327-349). Milan: Springer.

Anderson, M. C. \& Green, C. (2001). Suppressing unwanted memories by executive control. Nature, 410, 366-369.

Anderson, M. C., Ochsner, K. N., Kuhl, B., Cooper, J., Robertson, E., Gabrieli, S. W., Glover, G. H., \& Gabrieli, J. D. (2004). Neural systems underlying the suppression of unwanted memories. Science, 303, 232-235.

Baumeister, R. F. (1998). The self. In D. T. Gilbert, S. T. Fiske, \& G. Lindze (Eds.), Handbook of social psychology (pp. 680-740). New York: McGraw-Hill.

Bohanek, J. G., Fivush, R., \& Walker, E. (2005). Memories of positive and negative emotional events. Applied Cognitive Psychology, 19, 51-66.

Byrne, C. A., Hyman, I. E., \& Scott, K. L. (2001). Comparisons of memories for traumatic events and other experiences. Applied Cognitive Psychology, 15, 119-133.

Bywaters, M., Andrade, J., \& Turpin, G. (2004). Intrusive and non-intrusive memories in a non-clinical sample: the effects of mood and affect on imagery vividness. Memory, 12, 467-478.

Chambon, O., Cornillon-Jacouton, D., Germain, M. H., Assouline, B., Landazuri, F., \& Marie-Cardine, M. (1992). Bien-être subjectif et qualité de vie. Définitions, mesures et facteurs déterminants. Implications thérapeutiques. L'Information Psychiatrique, 5 (suppl), 57-62.

Christensen, T. C., Wood, J. V., \& Feldman Barrett, L. (2003). Remembering everyday experience through the prism of self-esteem. Personality and Social Psychology Bulletin, 29, 51-62.

Comblain, C., D'Argembeau, A., \& Van der Linden, M. (2005). Phenomenal characteristics of autobiographical memories for emotional and neutral events in older and younger adults. Experimental Aging Research, 31, 173-189. 
Conway, M. A. (2001). Sensory-perceptual episodic memory and its context: autobiographical memory. Philosophical Transactions of the Royal Society of London B Biological Sciences, 356, 1375-1384.

Conway, M. A. (2005). Memory and the self. Journal of Memory and Language, 53, 594-628.

Conway, M. A. \& Pleydell-Pearce, C. W. (2000). The construction of autobiographical memories in the self-memory system. Psychological Review, 107, 261-288.

Conway, M. A., Singer, J. A., \& Tagini, A. (2004). The self and autobiographical memory: Correspondence and coherence. Social Cognition, 22, 495-537.

Conway, M. A. \& Tacchi, P. C. (1996). Motivated confabulation. Neurocase, 2, 325339.

D'Argembeau, A., Comblain, C., \& Van der Linden, M. (2003). Phenomenal characteristics of autobiographical memories for positive, negative, and neutral events. Applied Cognitive Psychology, 17, 281-294.

D'Argembeau, A., Comblain, C., \& Van der Linden, M. (2005). Affective valence and the self-reference effect: influence of retrieval conditions. British Journal of Psychology, 96, 457-466.

D'Argembeau, A. \& Van der Linden, M. (2004). Phenomenal characteristics associated with projecting oneself back into the past and forward into the future: influence of valence and temporal distance. Consciousness and Cognition, 13, 844-858.

D'Argembeau, A. \& Van der Linden, M. (2007). Emotional aspects of mental time travel. Behavioral and Brain Sciences, 30, 220-221.

Denny, E. B. \& Hunt, R. R. (1992). Affective valence and memory in depression: dissociation of recall and fragment completion. Journal of Abnormal Psychology, 101, 575580.

Destun, L. M. \& Kuiper, N. A. (1999). Phenomenal characteristics associated with real and imagined events: the effects of event valence and absorption. Applied Cognitive Psychology, 13, 175-186. 
Fotopoulou, A., Conway, M., Griffiths, P., Birchall, D., \& Tyrer, S. (2007). Selfenhancing confabulation: revisiting the motivational hypothesis. Neurocase, 13, 6-15.

Fotopoulou, A., Conway, M. A., \& Solms, M. (2007). Confabulation: motivated reality monitoring. Neuropsychologia, 45, 2180-2190.

Greenwald, A. G. (1980). The totalitarian ego: Fabrication and revision of personal history. American Psychologist, 35, 603-618.

Johnson, M. K. (2006). Memory and reality. American Psychologist, 61, 760-771.

Johnson, M. K. \& Chalfonte, B. L. (1994). Binding complex memories: The role of reactivation and the hippocampus. In D. L. Schacter \& E. Tulving (Eds.), Memory systems 1994 (pp. 311-350). Cambridge, MA: MIT Press.

Johnson, M. K., Foley, M. A., Suengas, A. G., \& Raye, C. L. (1988). Phenomenal characteristics of memories for perceived and imagined autobiographical events. Journal of Experimental Psychology: General, 117, 371-376.

Kuiper, N. A. \& Derry, P. A. (1982). Depressed and nondepressed content selfreference in mild depressives. Journal of Personality, 50, 67-80.

Leary, M. R. (2004). The curse of the self: self-awareness, egotism, and the quality of human life. New York: Oxford University Press.

Leary, M. R. (2007). Motivational and emotional aspects of the self. Annual Review of Psychology, 58, 317-344.

Libby, L. K., \& Eibach, R. P. (2002). Looking back in time: Self-concept change affects visual perspective in autobiographical memory. Journal of Personality and Social Psychology, 82, 167-179.

McAdams, D. P. (2001). The psychology of life stories. Review of General Psychology, 5, 100-122.

Nigro, G. \& Neisser, U. (1983). Point of view in personal memories. Cognitive Psychology, 15, 467-482. 
Reisberg, D., Heuer, F., McLean, J., \& O'Shaughnessy, M. (1988). The quantity, not the quality, of affect predicts memory vividness. Bulletin of the Psychonomic Society, 26, 100-103.

Rogers, T. B., Kuiper, N. A., \& Kirker, W. S. (1977). Self-reference and the encoding of personal information. Journal of Personality and Social Psychology, 35, 677-688.

Rosenberg, M. (1965). Society and the adolescent self-image. Princeton, New Jersey: Princeton University Press.

Ross, M. \& Wilson, A. E. (2002). It feels like yesterday: self-esteem, valence of personal past experiences, and judgments of subjective distance. Journal of Personality and Social Psychology, 82, 792-803.

Rubin, D. C., Schrauf, R. W., \& Greenberg, D. L. (2003). Belief and recollection of autobiographical memories. Memory \& Cognition, 31, 887-901.

Sanz, J. (1996). Memory biases in social anxiety and depression. Cognition and Emotion, 10, 87-105.

Schacter, D. L. (1999). The seven sins of memory. Insights from psychology and cognitive neuroscience. American Psychologist, 54, 182-203.

Schacter, D. L. \& Addis, D. R. (2007). The cognitive neuroscience of constructive memory: remembering the past and imagining the future. Philosophical Transactions of the Royal Society of London B Biological Sciences, 362, 773-786.

Schaefer, A. \& Philippot, P. (2005). Selective effects of emotion on the phenomenal characteristics of autobiographical memories. Memory, 13, 148-160.

Sedikides, C. \& Green, J. D. (2000). On the self-protective nature of inconsistencynegativity management: using the person memory paradigm to examine self-referent memory. Journal of Personality and Social Psychology, 79, 906-922.

Sedikides, C. \& Green, J. D. (2004). What I don't recall can't hurt me: Information negativity versus information inconsistency as determinants of memorial self-defense. Social Cognition, 22, 4-29. 
Sedikides, C. \& Gregg, A. P. (2003). Portraits of the self. In M. A. Hogg \& J. Cooper (Eds.), Sage handbook of social psychology (pp. 110-138). London: Sage publications.

Sedikides, C., Gregg, A. P., \& Hart, C. M. (2007). The importance of being modest. In C. Sedikides \& S. Spencer (Eds.), The self: Frontiers in social psychology (pp. 163-184). New York: Psychology Press.

Sheen, M., Kemp, S., \& Rubin, D. C. (2006). Disputes over memory ownership: What memories are disputed? Genes, Brain and Behavior, 5, 9-13.

Sutin, A. R. \& Robins, R. W. (2005). Continuity and correlates of emotions and motives in self-defining memories. Journal of Personality, 73, 793-824.

Sutin, A. R., \& Robins, R. W. (2007). Phenomenology of autobiographical memories: The Memory Experiences Questionnaire. Memory, 15, 390-411.

Talarico, J. M., LaBar, K. S., \& Rubin, D. C. (2004). Emotional intensity predicts autobiographical memory experience. Memory and Cognition, 32, 1118-1132.

Tangney, J. P. (2003). Self-relevant emotions. In M. R. Leary \& J. P. Tangney (Eds.), Handbook of self and identity (pp. 384-400). New York: Guilford Press.

Taylor, S. E. \& Brown, J. D. (1988). Illusion and well-being: A social psychological perspective on mental health. Psychological Bulletin, 103, 193-210.

Tulving, E. (2002). Episodic memory: from mind to brain. Annual Review of Psychology, 53, 1-25.

Walker, R. W., Skowronski, J. J., \& Thompson, C. P. (2003). Life is pleasant-and memory helps keep it that way! Review of General Psychology, 7, 203-210.

Wheeler, M. A., Stuss, D. T., \& Tulving, E. (1997). Toward a theory of episodic memory: the frontal lobes and autonoetic consciousness. Psychological Bulletin, 121, 331354.

Wilson, A. E. \& Ross, M. (2003). The identity function of autobiographical memory: time is on our side. Memory, 11, 137-149. 
Table 1

Rating scales used to assess the phenomenological characteristics associated with remembering

\begin{tabular}{|c|c|}
\hline Characteristic & Brief description of rating scale \\
\hline Feeling of re-experiencing & While remembering the event, I feel as though I am mentally reliving it: $1=$ not at all, $7=$ completely. \\
\hline Visual details & My memory for this event involves visual details: $1=$ none, $7=$ a lot. \\
\hline Other sensory details & My memory for this event involves other sensory details (sounds, smells, and/or tastes): $1=$ none, $7=$ a lot. \\
\hline Location & I remember the location where the event took place: $1=$ not at all clear, $7=$ very clearly. \\
\hline Time & I remember the time of day when the event took place: $1=$ not at all clear, $7=$ very clear. \\
\hline Coherence & $\begin{array}{l}\text { While remembering the event, it comes to me as a coherent story and not as an isolated scene: } 1=\text { not at all, } \\
7=\text { completely. }\end{array}$ \\
\hline Verbal component & While remembering the event, it comes to me in words: $1=$ not at all, $7=$ a lot. \\
\hline Feeling emotions & $\begin{array}{l}\text { While remembering the event, I feel the emotions I felt when the event occurred: } 1=\text { not at all, } 7= \\
\text { completely. }\end{array}$ \\
\hline Real/imagine & $\begin{array}{l}\text { I believe the event in my memory really occurred in the way I remember it and that I have not imagined or } \\
\text { fabricated anything that did not occur: } 1=100 \% \text { imaginary, } 7=100 \% \text { real. }\end{array}$ \\
\hline What I did & I remember what I did during this event: 1 = not at all, 7 = very clearly. \\
\hline What I said & I remember what I said during this event: $1=$ not at all, 7 = very clearly. \\
\hline What I thought & I remember what I thought during this event: $1=$ not at all, $7=$ very clearly. \\
\hline Visual perspective & $\begin{array}{l}\text { A detailed paragraph adapted from Nigro and Neisser (1983) asked participants to report whether they } \\
\text { "saw" themselves in their memory (observer perspective) or saw the scene from their own perspective } \\
\text { (field perspective): from }-3=\text { entirely looking through my eyes to }+3=\text { entirely observing myself from an } \\
\text { outside point of view. }\end{array}$ \\
\hline Valence & When the event happened, my emotions were: $-3=$ very negative, $0=$ neutral, $+3=$ very positive. \\
\hline Personal importance & $\begin{array}{l}\text { This event is important to me (it involves an important theme or episode in my life): } 1=\text { not at all } \\
\text { important, } 7 \text { = very important. }\end{array}$ \\
\hline Reactivation & Since it occurred, I have thought or talked about this event: $1=$ not at all, $7=$ very often. \\
\hline Event age & How long ago did this event occur? (in months) \\
\hline
\end{tabular}


Table 2

Means and standard deviations of ratings for phenomenological characteristics

\begin{tabular}{|c|c|c|c|c|c|c|c|c|}
\hline & \multicolumn{4}{|c|}{ HSE individuals } & \multicolumn{4}{|c|}{ LSE individuals } \\
\hline & \multicolumn{2}{|c|}{ Self } & \multicolumn{2}{|c|}{ Other } & \multicolumn{2}{|c|}{ Self } & \multicolumn{2}{|c|}{ Other } \\
\hline $\begin{array}{l}\text { Feeling of re- } \\
\text { experiencing }\end{array}$ & $5.39(1.17)$ & $4.00(1.63)$ & $4.68(1.76)$ & $4.71(1.88)$ & $5.44(1.55)$ & $5.14(1.57)$ & $4.79(1.32)$ & $4.97(1.72)$ \\
\hline Visual details ${ }^{2}$ & $5.89(1.10)$ & $4.54(1.32)$ & $5.54(1.55)$ & $5.36(1.59)$ & $5.00(1.73)$ & $4.86(1.57)$ & $5.34(1.26)$ & $4.79(1.70)$ \\
\hline Other sensory details ${ }^{1}$ & $4.89(1.55)$ & $3.21(1.77)$ & $4.14(1.74)$ & $4.00(2.11)$ & $3.66(1.88)$ & $3.52(2.21)$ & $3.83(1.49)$ & $3.79(1.72)$ \\
\hline Location $^{3}$ & $6.75(0.59)$ & $5.82(1.51)$ & $6.39(0.99)$ & $6.50(1.32)$ & $6.31(1.17)$ & $6.38(1.04)$ & $6.17(1.44)$ & $6.34(1.20)$ \\
\hline Verbal component $^{1}$ & $4.54(1.79)$ & $4.07(1.96)$ & $3.79(1.95)$ & $4.61(1.64)$ & $3.79(2.02)$ & $3.66(1.88)$ & $3.83(1.54)$ & $4.07(1.91)$ \\
\hline Feeling of emotions ${ }^{2}$ & $5.79(1.17)$ & $4.71(1.82)$ & $4.82(1.66)$ & $5.82(1.25)$ & $5.10(1.54)$ & $5.41(1.35)$ & $4.79(1.84)$ & $5.31(1.77)$ \\
\hline Real/imagine $^{1}$ & $6.75(0.59)$ & $6.07(1.09)$ & $6.57(0.63)$ & $6.29(1$. & $6.21(0.98)$ & $5.69(1.34)$ & $5.86(1.19)$ & $5.86(1.22)$ \\
\hline What I did ${ }^{1}$ & $5.39(1.57)$ & $4.89(1.47)$ & $4.71(1.63)$ & $5.39(1.34)$ & $5.17(1.47)$ & $4.59(1.86)$ & $4.41(1.05)$ & $4.69(1.65)$ \\
\hline What I said ${ }^{3}$ & $4.71(1.88)$ & $4.07(2.07)$ & $4.25(1.78)$ & $4.79(2.04)$ & $4.28(1.91)$ & $4.00(1.89)$ & $4.07(1.33)$ & $4.31(1.87)$ \\
\hline What I thought ${ }^{2}$ & $5.61(1.40)$ & $4.68(1.70)$ & $5.32(1.51)$ & $5.96(1.17)$ & $5.28(1.39)$ & $5.17(1.61)$ & $5.38(1.63)$ & $5.34(1.04)$ \\
\hline
\end{tabular}

Note: HSE: high self-esteem; LSE: low self-esteem.

${ }^{1}$ Characteristic for which there was a significant interaction between valence and target $(p<.05)$.

${ }^{2}$ Characteristic for which there was a significant interaction between self-esteem, valence and target $(p<.05)$.

${ }^{3}$ Characteristic for which the valence by target interaction approached significance $(p<.10)$. 